Heavi I y $\mathrm{Cu}+$ doped anor phous $\mathrm{PbCl} 2 \mathrm{fi}$ I ms and aggr egat i on of $\mathrm{Cu}+\mathrm{i}$ ons due to crystal I i zat i on observed by $U$ spect roscopy

\begin{tabular}{|l|l|}
\hline 著者 & KONDO S, TANAKA N, SAl TO T \\
\hline $\begin{array}{l}\text { j our nal or } \\
\text { publ i cat i on t it l e }\end{array}$ & Journal of Physi cs D - Appl i ed Physi cs \\
\hline vol une & 33 \\
\hline number & 4 \\
\hline page range & $327-330$ \\
\hline year & $2000-02$ \\
\hline URL & ht t p: //hdl . handl e. net /10098/1526 \\
\hline
\end{tabular}




\title{
Heavily $\mathrm{Cu}^{+}$-doped amorphous $\mathrm{PbCl}_{2}$ films and aggregation of $\mathrm{Cu}^{+}$ions due to crystallization observed by UV spectroscopy
}

\author{
S Kondo, N Tanaka and T Saito \\ Research Centre for Development of Far-Infrared Region, Fukui University, Bunkyo, \\ Fukui 910-8507, Japan
}

\begin{abstract}
Heavily $\mathrm{Cu}^{+}$-doped amorphous $\mathrm{PbCl}_{2}$ has been obtained by quench deposition of the mixture of $\mathrm{PbCl}_{2}$ and $\mathrm{CuCl}$. Upon crystallization, the large majority of $\mathrm{Cu}^{+}$ions aggregate to form $\mathrm{CuCl}$ precipitates embedded in the crystalline $\mathrm{PbCl}_{2}$ matrix. The present experiment opens up the possibility of producing densely dispersed CuCl clusters in a controlled manner in $\mathrm{PbCl}_{2}$ films.
\end{abstract}

\section{Introduction}

One of the interests in producing film material rather than growing single crystals is the possibility of introducing high concentration impurities. For example, $\mathrm{Cu}^{+}$-doped $\mathrm{KCl}$ films with the $\mathrm{Cu}^{+}$concentration ranging from $10^{20}$ to $10^{21} \mathrm{~cm}^{-3}$ have been attained (for the purpose of device application such as ultraviolet (UV) optical filters) by resistive co-evaporation of $\mathrm{KCl}-\mathrm{CuCl}$ mixed powders with nominally $1-15 \mathrm{~mol} \%$ CuCl concentration [1]. Recentiy, we doped $\mathrm{Cdi}_{2}$ films with trivalent $\mathrm{Bi}^{3+}$ ions up to $10 \mathrm{~mol} \%$ of cation concentration [2], despite the different valencies between the host and guest cations. The heavy doping was achieved in the amorphous form of the films by quench deposition of the mixture of $\mathrm{CdI}_{2}$ and $\mathrm{Bil}_{3}$. Crystallization of the films resulted in well defined two-molecule $\mathrm{BiI}_{3}$ clusters densely monodispersed in the $\mathrm{CdI}_{2}$ polycrystalline matrix. In the present work we investigated $\mathrm{PbCl}_{2}$ films heavily doped with $\mathrm{Cu}^{+}$ions, to study the opposite case of non-stoichiometric impurity, i.e. the impurity having smaller valency than the host cation.

Both $\mathrm{PbCl}_{2}$ [3] and $\mathrm{CuCl}$ [4] can be rendered amorphous by quench deposition. The two compounds have similar vapour pressure; for instance the temperature at which the vapour pressure becomes $1 \mathrm{Torr}(130 \mathrm{~Pa})$ is $547^{\circ} \mathrm{C}$ for $\mathrm{PbCl}_{2}$ and $546^{\circ} \mathrm{C}$ for $\mathrm{CuCl}$. This may provide a good condition for preparing an amorphous solid solution by the co-evaporation of their mixture. Furthermore, the small ionic radius of the $\mathrm{Cu}^{+}$ion $(0.96 \AA[5])$ compared to the $\mathrm{Pb}^{2+}$ ion radius (1.24-1.28 $\AA$ [5]) makes it favourable for the $\mathrm{Pb}^{2+}$ ions to be substituted by the $\mathrm{Cu}^{+}$ions in the amorphous environment. Aggregation of the substituted $\mathrm{Cu}^{+}$ions may be observed by exciton spectroscopy, as indeed demonstrated for $\mathrm{CuCl}$ nanocrystal growth in alkali halide single crystals [6]. These considerations motivated the present work.

\section{Experimental details}

For the preparation of the heavily $\mathrm{Cu}^{+}$-doped $\mathrm{PbCl}_{2}$ films, mixed powders of $\mathrm{PbCl}_{2}$ and $\mathrm{CuCl}$ were put into silica-tube containers. The containers were evacuated to $5 \times 10^{-4} \mathrm{~Pa}$ at $200^{\circ} \mathrm{C}$ for $24 \mathrm{~h}$ and sealed to get vacuum-sealed ampoules of the mixtures. The ampoules were heated to $555^{\circ} \mathrm{C}$, held at that temperature for $1 \mathrm{~h}$, and then quenched in ice water to achieve homogeneity in the concentration of the mixtures.

Amorphous films of the thus-prepared mixtures were obtained by quench-deposition described in [7]. In brief, the deposition was carried out on a fused-silica substrate cooled to $77 \mathrm{~K}$ in a vacuum of about $9 \times 10^{-6} \mathrm{~Pa}$ using a tungsten basket heating element placed $8 \mathrm{~cm}$ in front of the substrate; the deposition rate was about $20 \mathrm{~nm} \mathrm{~min}^{-1}$. Such a high deposition rate was considered to be favourable for achieving the nominal composition ratio of $\mathrm{PbCl}_{2}$ and $\mathrm{CuCl}$ in the films, although the resulting composition ratio was not analysed. The thicknesses of the films were determined by an interference method [8].

The doped $\mathrm{PbCl}_{2}$ films were investigated by an improved UV absorption spectroscopy, described in [2]. The method is based on simultaneous measurements of transmittance and reflectance from which accurate optical densities of weaklyabsorbing films can be determined. The measurements were made in situ on a film annealed at various temperatures.

\section{Resulis}

Figure 1 illustrates the effect of annealing on the absorption spectra of a quench-deposited amorphous $\mathrm{PbCl}_{2}: \mathrm{CuCl}$ film. The nominal concentration of $\mathrm{CuCl}$ is $10 \mathrm{~mol} \%$. The thickness of the film is about $850 \mathrm{~nm}$. Spectral 


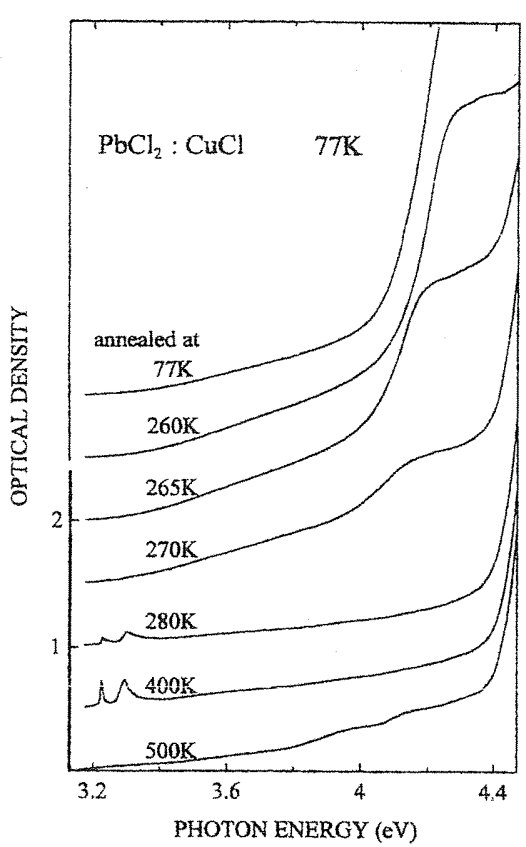

Figure 1. The effect of annealing on the absorption spectrum of a quench-deposited amorphous $\mathrm{PbCl}_{2}: \mathrm{CuCl}$ film of nominal $10 \mathrm{~mol} \% \mathrm{CuCl}$ concentration. All the spectra are measured at $77 \mathrm{~K}$ for the increasing annealing temperatures indicated. The scale on the ordinate is given only for the lowernost spectrum. The film thickness is about $850 \mathrm{~nm}$.

measurements were carried out at $77 \mathrm{~K}$ for increasing annealing temperatures $\left(T_{a}\right)$. Heating and cooling in each annealing cycle were performed at rates of 1 and $10 \mathrm{~K} \mathrm{~min}^{-1}$, respectively.

In order to explain the annealing behaviour, it is convenient to briefly describe the transient spectra during crystallization of undoped amorphous $\mathrm{PbCl}_{2}$ films. The absorption spectrum of undoped amorphous $\mathrm{PbCl}_{2}$ films is characterized by a non-excitonic, prominent first band peaking at $4.418 \mathrm{eV}$ (absorption edge, about $4.0 \mathrm{eV}$ ) [9]. On slow heating $\left(1 \mathrm{~K} \mathrm{~min}^{-1}\right)$, they show sharp crystallization in a narrow temperature range of $1.5 \mathrm{~K}$ near $282 \mathrm{~K}$ [3], with the first band transformed to a sharp excitonic peak located at $4.66 \mathrm{eV}$ (absorption edge, about $4.4 \mathrm{eV}$ ). A detailed measurement [10] achieved at a very slow heating rate of $0.05 \mathrm{~K} \mathrm{~min}^{-1}$ in the range $281.5-283 \mathrm{~K}$ revealed that three competing spectral structures showed up during crystallization. Of the three, the lowest-energy structure (about $4.2 \mathrm{eV}$ ), A, which was associated with nucleation in the films, was observed at the initial stage of crystallization. With the progress of crystallization, structure A became weaker and finally disappeared, leaving behind the excitonic peak.

As seen from figure 1 the absorption edge of the present film changes from about $4.0 \mathrm{eV}$ for $T_{a}=77 \mathrm{~K}$ (asdeposited film) to about $4.4 \mathrm{eV}$ for $T_{a} \geqslant 280 \mathrm{~K}$, reflecting crystallization of the film. The structure appearing around $4.2 \mathrm{eV}$ for $260 \mathrm{~K} \leqslant T_{a} \leqslant 270 \mathrm{~K}$ corresponds to structure A of the undoped $\mathrm{PbCl}_{2}$ film (note that the optical density at the peak $(4.418 \mathrm{eV})$ of the first band for $T_{a}=77 \mathrm{~K}$ amounts to 22

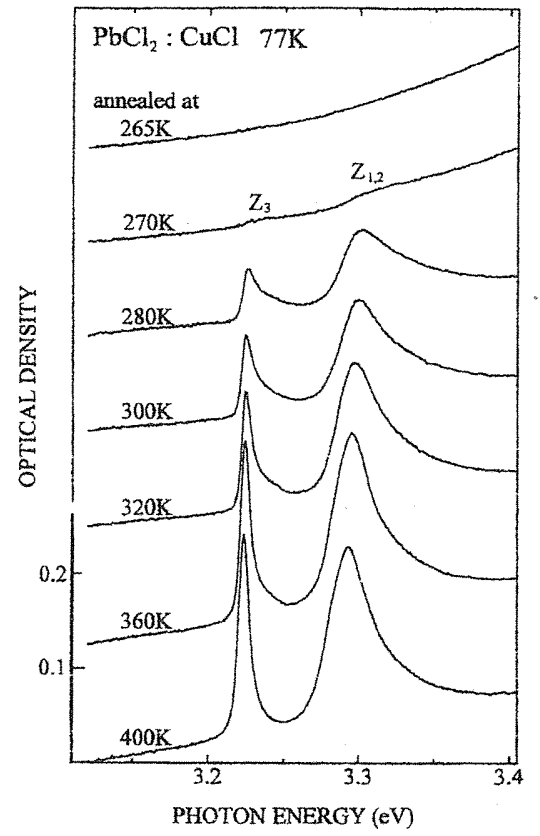

Figure 2. Details of the effect of annealing $\left(T_{a} \geqslant 265 \mathrm{~K}\right)$ on the absorption spectra at $77 \mathrm{~K}$ in the region of $\mathrm{CuCl}$ exciton absorption, measured for the same film as that for the spectra in figure 1.

when calculated for an undoped film of $850 \mathrm{~nm}$ thickness). Therefore, we can conclude that the crystallization of the present film starts to occur at about $260 \mathrm{~K}$ and is completed at about $280 \mathrm{~K}$. The $\mathrm{Cu}^{+}$ions in the filu have the effect of lowering the crystallization temperature and widen the temperature range where the crystallization proceeds.

After completion of crystallization there arise new structures at energies in the range $3.2-3.3 \mathrm{eV}$ due to exciton absorption of crystalline $\mathrm{CuCl}$. This indicates that the $\mathrm{Cu}^{+}$ ions aggregate to form $\mathrm{CuCl}$ clusters during the final state of crystallization of the host. It is interesting to note that the temperature at which crystalline $\mathrm{CuCl}$ is precipitated in the $\mathrm{PbCl}_{2}$ matrix is much (by about $100 \mathrm{~K}$ ) higher than the crystallization temperature (177 K [4]) of amorphous $\mathrm{CuCl}$.

Figure 2 presents magnified spectra of the same film in the region of $\mathrm{CuCl}$ exciton absorption to show the growth process of crystalline $\mathrm{CuCl}$. Although there is no trace of exciton absorption for $T_{a}=265 \mathrm{~K}$, weak structures reminiscent of $\mathrm{Z}_{3}$ and $\mathrm{Z}_{1,2}$ excitons are observed for $T_{a}=$ $270 \mathrm{~K}$ and they grow to clear peaks at $T_{a}=280 \mathrm{~K}$. Upon further annealing, they sharpen in shape and become strong in intensity (by about 20\%), accompanying a small red shift of the peak energies (by a few milli-electron volts) (as evaluated by a lineshape analysis [11]). The integrated excitonabsorption intensity for $T_{a}=400 \mathrm{~K}$ corresponds to a $13 \mathrm{~nm}$ thickness of a $\mathrm{CuCl}$ film. From this, the $\mathrm{CuCl}$ concentration with which the $\mathrm{CuCl}$ precipitates are embedded in the $\mathrm{PbCl}_{2}$ polycrystalline matrix is calculated to be $3.1 \mathrm{~mol} \%$.

Further annealing at temperatures above $400 \mathrm{~K}$ gave rise to an abrupt reduction in the absorption intensity of the excitons. In fact, the exciton absorption decreased 10 times 
for $T_{a}=440 \mathrm{~K}$ and completely disappeared for $T_{a}=500 \mathrm{~K}$ instead, new weak structures appeared around 3.95 and $4.15 \mathrm{eV}$, as seen from the lowermost curve in figure 1 . The precipitated $\mathrm{CuCl}$ is considered to be dissociated, yielding new absorotion centres responsible for the structures.

\section{Discussion}

In situ absorption spectroscopy has been shown to provide a powerful means of studying the growth of copper halide nanocrystals in alkali halides [6]. Exciton lines are used as a signature of crystallinity and a broad absorption peak measures the number of $\mathrm{Cu}^{+}$ions. The present study demonstrates that a similar method is also useful to trace CuCl in $\mathrm{PbCl}_{2}$.

Previously we reported [4] that exciton absorption in CuCl was observed even in the amorphous state because of the very small radius of the exciton (the Bohr radius is $6.8 \AA$ for the $Z_{3}$ exciton [12]), which is so small that the exciton was able to exist within the short-range order. In the amorphous $\mathrm{PbCl}_{2}: \mathrm{CuCl}$ film, however, no trace of CuCl exciton transitions is discemible, as shown in section 3. Presumably, $\mathrm{Cu}^{+}$ions are dispersed as dimers in the amorphous etrvironment; the dimerization is due to the necessity of electrical neutrality, i.e. $\mathrm{Pb}^{2+}$ ion can only be replaced by two $\mathrm{Cu}^{+}$ions.

The assumption may be accessible based on an ion-glass model [9] of amorphous lead halides. The model proposed that each $\mathrm{Pb}^{2+}$ ion in amorphous $\mathrm{PbX}_{2}(\mathrm{X}=\mathrm{Br}, \mathrm{Cl}, \mathrm{F})$ was surrounded by nine neighbouring $X^{-}$ions without any well defined site symmetry around it. By using an effective $\mathrm{Pb}^{2+}-\mathrm{X}^{-}$-distance $d$ for the superionic assembly $[\mathrm{PbX}]^{7-}$, the logarithmic fuctuation $\Delta d / d$ was shown to have a Gaussian distribution with the full-width at half-maximum of about 0.05 . Therefore, there may be a possibility of having a large enough $d$ for the superionic assembly $[\mathrm{PbX}]^{7-}$ to be replaced by a quasicomplex of $\left[\mathrm{Cu}_{2} \mathrm{X}_{9}\right]^{7-}$. The small ionic radius of the $\mathrm{Cu}^{+}$ion compared to the $\mathrm{Pb}^{2+}$ ion radius is considered to be favourable for heavily doping amorphous $\mathrm{PbCl}_{2}$ with $\mathrm{Cu}^{+}$ions in such a manner.

Since crystallization of the film requires $\Delta d / d \rightarrow$ 0 , it is expected that the large majority of the densely dispersed $\mathrm{Cu}^{+}$dimers aggregate to form CuCl clusters during crystallization, yielding CuCl crystallites. This is evidenced by the appearance of exciton absorption for $T_{a}=280 \mathrm{~K}$ (figure 2). Other $\mathrm{Cu}^{+}$dimers which still occupy $\mathrm{Pb}^{2+}$ ion sites may contribute to the growth of the crystallites at higher annealing temperatures $\left(280 \mathrm{~K}<T_{a} \leqslant 400 \mathrm{~K}\right)$. The growth of the crystallites leads to the small increase of the exciton absorption intensity (by about 20\%) and the small red shift of the exciton peak (by a few milli-electron volts). The red shift is attributable to relaxation of the quantum size effect on the exciton due to the growth of the crystallites.

It is instructive to compare the present result with previous work on heavily $\mathrm{Bi}^{3+}$-doped $\mathrm{CdI}_{2}$ films [2]. The heavy doping was achieved by quench-deposition, yielding amorphous films with three $\mathrm{Cd}^{2+}$ ions replaced by two $\mathrm{Bi}^{3+}$ ions up to $10 \mathrm{~mol} \%$ of $\mathrm{BiI}_{3}$ concentration. After crystallization of the films, stable $\mathrm{Bi}^{3+}$ dimers existed without forming higher-order clusters. In the case of the present result for $\mathrm{PbCl}_{2}: \mathrm{CuCl}$, however, larger clusters were already observed for the film just after crystallization. The difference in the clustering behaviour between the two systems may be explained in terms of dimensionality. In the $\mathrm{CdI}_{2}: \mathrm{BI}_{3}$ system, where both $\mathrm{CdI}_{2}$ and $\mathrm{Bir}_{3}$ are layer compounds, clustering of $\mathrm{Bi}^{3+}$ ions is considered to occur in two dimensions, i.e. within single cation layers. Therefore, it is difficult to yield larger clusters, unlike in the case of the $\mathrm{PbCl}_{2}$ :CuCl system where a three-dimensional process proceeds.

In [6], the growth of $\mathrm{CuCl}$ nanocrystals was studied by UV spectroscopy for a $\mathrm{Cu}^{+}$-doped single crystal of $\mathrm{NaCl}$ with the nominal 0.2 mol\% fraction of $\mathrm{CuCl}$. Although the $\mathrm{CuCl}$ concentration is very small, aggregation and dissociation of $\mathrm{CuCl}$ are similar in behaviour to the present $\mathrm{PbCl}_{2}: \mathrm{CuCl}$ case. The growth of $\mathrm{CuCl}$ nanocrystals in the $\mathrm{NaCl}$ crystal occurred for annealing temperatures $T_{a}$ above $275 \mathrm{~K}$, with the $Z_{3}$ and $Z_{1,2}$ exciton absorption enhanced and with their peak positions redshifted with increasing $T_{a}$ up to $450 \mathrm{~K}$. For $T_{a}>450 \mathrm{~K}$ the exciton absorption decreased, and at $T_{a}=600 \mathrm{~K}$ all chusters were destroyed, exhibiting a broad absorption band at $4.86 \mathrm{eV}$ due to single $\mathrm{Cu}^{+}$ions. In the present $\mathrm{PbCl}_{2}$ : $\mathrm{CuCl}$ system the grown $\mathrm{CuCl}$ crystallites started to decrease at nearly the same $T_{a}$ (above $400 \mathrm{~K}$ ), despite the much higher $\mathrm{CuCl}$ concentration. The weak structures observed at 3.95 and $4.15 \mathrm{eV}$ for the lowest curve in figure 1 are attributed to absorption due to destroyed $\mathrm{CuCl}$ crystallites, i.e. $\mathrm{Cu}^{+}$dimers. $\left(\mathrm{Cu}^{+}\right.$dimers in the amorphous $\mathrm{PbCl}_{2}$ :CuCl film may also absorb light of similar photon energies; however, such absorption, being considered to be hidden by the strong absorption for the host $\mathrm{PbCl}_{2}$, is not observed in figure 1.)

\section{Conclusion}

Heavily $\mathrm{Cu}^{+}$-doped amorphous $\mathrm{PbCl}_{2}$ was obtained by quench deposition of the mixture of $\mathrm{PbCl}_{2}$ and $\mathrm{CuCl}$, despite the different valencies between the cations of the two compounds. The $\mathrm{Pb}^{2+}$ ion in the superionic assembly $\left[\mathrm{PbCl}_{9}\right]^{7-}$ with a large $\mathrm{Pb}^{2+}+\mathrm{Cl}$ distance in the amorphous enviromment has a possibility of being replaced by two $\mathrm{Cu}^{+}$ions, forming a quasicomplex $\left[\mathrm{Cu}_{2} \mathrm{Cl}_{9}\right]^{7 \cdots}$. Upon crystallization of the host environment, the large majority of $\mathrm{Cu}^{+}$ions aggregate to form $\mathrm{CuCI}$ precipitates embedded in the crystalline $\mathrm{PbCl}_{2}$ matrix. The present experiment opens up the possibility of producing densely dispersed $\mathrm{CuCl}$ clusters in a controlled manner in $\mathrm{PbCl}_{2}$ films. For example, the size of the clusters is expected to be controllable by developing annealing performance as well as by varying the $\mathrm{CuCl}$ mole fraction. Studies on achieving densely dispersed small clusters (nanocrystals) with a specified size distribution are in progress and the results will be reponted later.

\section{Acknowledgments}

This work was partly supported by the Grant-in-Aid for Scientific Research from the Ministry of Education, Science, Sports and Culture, and also partly by the Hokuriku Industrial Advancement Centre. 


\section{Pererences}

[1] Oliveira L, Cruz C M G S, Silva M A P and Siu Li M 1994 Thin Solid Films 250273

[2] Kondo S, Suzuki T and Satito T 1988 J. Phys. D: Appl. Phys. 312733

[3] Kondo S, Maruyama H and Saito T 1995 Phys. Status Solidi a 147453

[4] Kondo S and Sekì T 1992 Mater. Sci. Eng. 815133

[5] Kittel C 1986 Introduction to Solid State Physics 6th edn (New York: Wiley) p 76
[6] Haselhoff $M$ and Weber H-J 1988 Phys, Rev. B 585052

[7] Kondo S, Itoh T, Saito T and Mekata M 1991 J. Phys. Soc. Japan 602764

[8] Kondo S and Matsumoto H 1981 J. Phys. Soc. Japan 50 3047

[9] Kondo S 1996 Phys. Status Solidi a 153529

[10] Kondo S, Maruyama H and Saito T 1996 Phys. Status Solidi a 156151

[11] Kondo S and Seki T 1993 Phys. Status Solidi b $176 \mathrm{~K} 113$

[12] Honerlage B, Klingshirn C and Grun J B 1976 Phys. Status Solidi b 78599 